\title{
Near-infrared low-level laser stimulation of telocytes from human myometrium
}

\author{
Razvan-Alexandru Campeanu • Beatrice Mihaela Radu • Sanda Maria Cretoiu • \\ Daniel Dumitru Banciu • Adela Banciu • Dragos Cretoiu • Laurentiu Mircea Popescu
}

Received: 15 January 2014 / Accepted: 24 April 2014 / Published online: 29 May 2014

(C) The Author(s) 2014. This article is published with open access at Springerlink.com

\begin{abstract}
Telocytes (TCs) are a brand-new cell type frequently observed in the interstitial space of many organs (see www. telocytes.com). TCs are defined by very long (tens of micrometers) and slender prolongations named telopodes. At their level, dilations - called podoms $(\sim 300 \mathrm{~nm})$, alternate with podomers $(80-100 \mathrm{~nm})$. TCs were identified in a myometrial interstitial cell culture based on morphological criteria and by CD34 and PDGF receptor alpha (PDGFR $\alpha$ ) immunopositivity. However, the mechanism(s) of telopodes formation and/or elongation and ramification is not known.
\end{abstract}

Razvan-Alexandru Campeanu and Beatrice Mihaela Radu contributed equally to this work.

R.-A. Campeanu • B. M. Radu • D. D. Banciu • A. Banciu Department of Anatomy Animal Physiology and Biophysics, Faculty of Biology, University of Bucharest, 050095 Bucharest, Romania

R.-A. Campeanu

Neuroscience Area, International School for Advanced Studies (SISSA), 34136 Trieste, Italy

B. M. Radu

Department of Neurological and Movement Sciences, University of Verona, 37134 Verona, Italy

S. M. Cretoiu • D. Cretoiu $\cdot$ L. M. Popescu $(\square)$

Department of Cellular and Molecular Medicine, Carol Davila

University of Medicine and Pharmacy, 050474 Bucharest, Romania

e-mail: LMP@jcmm.org

S. M. Cretoiu

Department of Ultrastructural Pathology, Victor Babeș National Institute of Pathology, 050096 Bucharest, Romania

D. Cretoiu

Department of Molecular Medicine, Victor Babeș National Institute of Pathology, 050096 Bucharest, Romania

L. M. Popescu

Division of Advanced Studies, Victor Babeș National Institute of Pathology, 050096 Bucharest, Romania
We report here the low-level laser stimulation (LLLS) using a 1,064-nm neodymium-doped yttrium aluminum garnet (Nd:YAG) laser (with an output power of $60 \mathrm{~mW}$ ) of the telopodal lateral extension (TLE) growth in cell culture. LLLS of TCs determines a higher growth rate of TLE in pregnant myometrium primary cultures $(10.3 \pm 1.0 \mu \mathrm{m} / \mathrm{min})$ compared to nonpregnant ones $(6.6 \pm 0.9 \mu \mathrm{m} / \mathrm{min})$. Acute exposure (30 min) of TCs from pregnant myometrium to $1 \mu \mathrm{M}$ mibefradil, a selective inhibitor of T-type calcium channels, determines a significant reduction in the LLLS TLE growth rate $(5.7 \pm 0.8 \mu \mathrm{m} / \mathrm{min})$ compared to LLLS per se in same type of samples. Meanwhile, chronic exposure (24 h) completely abolishes the LLLS TLE growth in both nonpregnant and pregnant myometria. The initial direction of TLE growth was modified by LLLS, the angle of deviation being more accentuated in TCs from human pregnant myometrium than in TCs from nonpregnant myometrium. In conclusion, TCs from pregnant myometrium are more susceptible of reacting to LLLS than those from nonpregnant myometrium. Therefore, some implications are emerging for low-level laser therapy (LLLT) in uterine regenerative medicine.

Keywords $1064 \mathrm{Nd}$ :YAG laser · Low-level laser stimulation . Telocytes $\cdot$ Telopodes $\cdot$ Human myometrium $\cdot$ Pregnancy

\section{Introduction}

Thorough knowledge of the structure of the uterine wall is essential to contribute to the understanding of reproductive function. Alterations of normal function of human uterus are reported in pregnant and nonpregnant state. Often these disorders implicate the reproductive function and are difficult to manage in the absence of a specific treatment.

Telocytes (TCs) were recently described as stromal/ interstitial cells found in many organs (for details, visit 
www.telocytes.com) including the human uterus [1, 2]. Transmission electron microscopy is considered to be the most suited method for TCs identification [3, 4]. TCs can also be identified by CD34 and PDGF receptor alpha $(\operatorname{PDGFR} \alpha)$ immunohistochemistry [5-8]. The function of TCs is not well understood yet; however, evidence points towards a role of telopodes in the coordination of the surrounding cells by exosome/ectosome release [9-11]. TCs display electrical activity [12] and have been observed to form homo- and heterocellular junctions [4]. Currently, cell culture has emerged as an important research method for studying the TCs behavior [13]. Time-lapse microscopy revealed dynamically moving telopodes which were supposed to serve as guiding wires for other cells in coculture [12]. The process standing behind this dynamics of telopodes is still to be understood, and information about the biophysical properties of the telopodal plasma membrane would bring new insights.

To this purpose, we have decided to stimulate by nearinfrared (NIR) laser the telopodes for testing their ability to grow and the possibility of stimulation of telopodal lateral extension (TLE) growth. The ability of TCs to form homoand heterocellular contacts with various cell types (e.g., myocytes, immune cells, stem cells, etc.) in different organs [14-16] has a tremendous medical impact. The possibility of influencing their dynamics in vitro and in vivo by means of low-level NIR guidance can open new perspectives in uterine regenerative medicine.

The idea of optical stimulation and guidance was extensively tested on primary neuronal cell cultures or neuronal cell lines (for review, see [17-22] using low-level laser stimulation (LLLS)). Moreover, other types of cells, such as Swiss 3T3 cells, extend pseudopodia towards NIR light sources [23]. Although TCs extend long telopodes with dynamic movement [12] and are good candidates for optical stimulation by means of LLLS, the topic is still uncovered. The goal of our study was to identify, for the first time, the differences of TC response to LLLS between nonpregnant and pregnant human myometria.

\section{Materials and methods}

Tissue samples

Five biopsies of human myometrium were obtained from different hysterectomy specimens (benign indications) of nonmenopausal women (mean age 42.5 years). Other five specimens were obtained from the uteri of pregnant primipara women (between 38 and 40 weeks of gestation, mean age 32.5 years), at the time of cesarean section. All patients received information about the study and signed an informed consent file. All experiments have been carried out in accordance with the EU guidelines and approved by the Bioethics
Committee of "Carol Davila" University of Medicine Bucharest.

Cell cultures

Human myometrial samples were collected into sterile tubes containing Dulbecco's modified Eagle medium (DMEM) supplemented with fetal bovine serum (FBS) $2 \%$, HEPES $(1.5 \mathrm{mM})$, as well as $10,000 \mathrm{IU} / \mathrm{ml}$ penicillin, $0.2 \mathrm{mg} / \mathrm{ml}$ streptomycin, and $0.50 \mathrm{mg} / \mathrm{ml}$ amphotericin (Sigma Chemical), placed on ice and transported to the cell culture laboratory. Samples were processed within $30 \mathrm{~min}$ from surgery. Cells were cultured using the procedure described in detail elsewhere [12].

Immunofluorescence

Immunofluorescent staining was performed on cells cultured on coverslips, at fourth passage. The cells were fixed in $2 \%$ paraformaldehyde for $10 \mathrm{~min}$, washed in phosphate-buffered saline (PBS), and then incubated in PBS containing $1 \%$ bovine serum albumin (BSA) for another $10 \mathrm{~min}$. Cells were washed again and permeabilized in PBS containing $0.075 \%$ saponin for 10 min (all reagents were from Sigma Chemical, St. Louis, MO, USA). Incubation with the primary antibodies was performed for $1 \mathrm{~h}$, at room temperature, using antihuman antibodies: CD34, goat polyclonal (sc-7045), 1:50 (Santa Cruz Biotechnology, Inc., Heidelberg, Germany), and PDGFR $\alpha$ rabbit polyclonal (sc-338), 1:100 (Santa Cruz Biotechnology, Inc., Heidelberg, Germany). After three serial rinses, the bound primary antibodies were detected with secondary donkey anti-goat antibody conjugated to Alexa Fluor 546, 1:250, and goat anti-rabbit antibody conjugated to Alexa Fluor 488, 1:250; all were from Invitrogen Molecular Probes, Eugene, OR, USA. Nuclei were finally counterstained with $1 \mu \mathrm{g} / \mathrm{ml}$ 4',6-diamidino-2-phenylindole (DAPI) (Sigma-Aldrich).

Negative controls were obtained following the same protocol, but omitting the primary antibodies. Samples were examined under a Nikon TE300 microscope equipped with a Nikon DS-Qil camera, Nikon PlanApo $\times 20$ and $\times 40$ objectives, and the appropriate fluorescence filters.

Near-infrared low-level laser stimulation

The optical stimulation of the TLE growth was done by means of a MicroTweezers Module twinflex Rel. 4.2 system (Carl Zeiss, Germany) mounted on an inverted microscope AxioObserver D1 (Carl Zeiss, Germany). We used a diodepumped solid-state IR neodymium-doped yttrium aluminum garnet (Nd:YAG) laser (Ventus 1064-3000, Carl Zeiss), continuous wave $(\mathrm{cw})$ mode, wavelength $1,064 \mathrm{~nm}$, power $3,000 \mathrm{~mW}$, transverse mode $\mathrm{TEM}_{00}$, beam divergence 
$<1 \mathrm{mrad}$, beam diameter $2.5 \mathrm{~mm}$. The parameters of the laser beam (e.g., output power, spot size, position) were controlled by the RoboSoftware 4.3 Pro SP2 (Carl Zeiss, Germany). The beam was focused on the cells through a Plan-Neofluar $\times 100$ / 1.3 oil objective. During telopodal stimulation, the laser output power was set to $60 \mathrm{~mW}$, and the spot size was $2 \mu \mathrm{m}$. The laser spot size was controlled and done by optically defocusing the beam to rich the desired size, similar to [17]. The beam was applied on the telopode surface as pulses of $1 \mathrm{~s}$ length with a frequency of $0.1 \mathrm{~Hz}$ for appropriate periods of stimulation. The whole optical setup is placed on top of a vibration-isolated table (Thorlabs, USA).

The experiments of optical stimulation of TCs consist in exposing a viable telopode to a laser beam (as described above) by placing approximately half of the laser beam on a TLE. The laser beam position is continuously adjusted as the telopode expands laterally. The TLE growing speed has been calculated from the moment it started to grow after being stimulated with the laser to the moment it stopped growing and started to retract; considering the growing distance in a given time, the average growing speed was estimated.

TCs were continuously perfused using a MPS-2 multichannel perfusion system with a micromanifold of $100 \mu \mathrm{m}$ (World Precision Instruments, USA) at a rate flow of $1 \mu \mathrm{l} / \mathrm{s}$. In the acute experiment, LLLS is performed before (control) and after $30 \mathrm{~min}$ of mibefradil $(1 \mu \mathrm{M}$ ) (from Sigma-Aldrich, St. Louis, MO, USA) continuous perfusion on two different telopodes of the same TC. TCs were chronically ( $24 \mathrm{~h})$ exposed to mibefradil $(1 \mu \mathrm{M})$ by overnight incubation at $37^{\circ} \mathrm{C}$ in a humidified atmosphere $\left(5 \% \mathrm{CO}_{2}\right.$ in air), and LLLS was performed in the next day. In both types of treatments, mibefradil is prepared into DMEM supplemented with FBS $10 \%$.

\section{Statistical analysis}

Data are analyzed and plotted using Excel (Microsoft, Redmond, WA, USA). The values of growth rate are reported as mean $\pm \mathrm{SD}$. Unpaired Student's $t$ test was employed to compare the growth rates upon LLLS on TCs from nonpregnant vs. pregnant myometrium. Meanwhile, paired Student's $t$ test was used to compare growth rates upon LLLS on TCs from pregnant myometrium before and after mibefradil treatment.

\section{Results}

In this study, we identified TCs in myometrial cell culture, using accepted criteria: morphology under phase contrast microscopy and immunocytochemistry criteria in fluorescence microscopy. TCs were seen as cells with very long telopodes in phase contrast microscopy (Fig. 1a). In fluorescence microscopy, CD34-positive cells were seen (Fig. 1b) having approximately the same morphology with PDGFR $\alpha$ positive cells (Fig. 1c).

The mean duration of TLE stimulation was around $30 \mathrm{~min}$ or above, and it was chosen depending on the moment TLE stopped growing or retraction. The period of TLE exposure to LLLS and the beam laser characteristics are comparable to the previous reports on in vitro neuronal stimulation $[17,18]$.

Reactivity of telopodes to LLLS varies in pregnant and nonpregnant myometrium. There is a net difference between the reactivities to optical stimulation of telopodes originating from pregnant (Fig. $2 b(a-c)$ ) or nonpregnant uterus (Fig. $2 \mathrm{a}(\mathrm{a}-\mathrm{c})$ ). Telopodes from pregnant uterus are more prone to extend upon LLLS compared to those from nonpregnant uterus. The maximal length of TLE upon LLLS in telopodes from pregnant myometrium was $7.4 \mu \mathrm{m}$, while only a maximal growth of $2.2 \mu \mathrm{m}$ was attained in telopodes from pregnant myometrium. It should be also taken into account the difficulty to obtain an LLLS TLE growth in TCs from nonpregnant myometrium, the required time of stimulation sometimes being three times higher than that in pregnant myometrium.

We have found a speed rate of TLE growth of $10.3 \pm$ $1.0 \mu \mathrm{m} / \mathrm{min}(n=6)$ in TCs from pregnant myometrium, which is significantly higher than $6.6 \pm 0.9 \mu \mathrm{m} / \mathrm{min}(n=5)$ in TCs from nonpregnant myometrium, $p<0.01$, unpaired Student's $t$ test (Fig. 3).

In both preparations, telopodes seem to accumulate a big part of their resources near the stimulation area, and the laser beam with finger-like structures was probed. In some experiments, the telopode looks like it is breaking off its old connection, maintaining only thin "anchors" beyond the point of stimulation.

We tested whether we could deviate by LLLS the direction of TLE growth by at least $30^{\circ}$ away from the original direction of TC growth, following a protocol previously described on NG108 neuroblastoma cell line [24]. The black arrows in Fig. 2a, b indicate the direction of the TLE. As we are working on human tissue, it was impossible to accumulate a large number of data as in previous studies on neuronal guidance. We have obtained a deviation below or up to $30^{\circ}$ in the TCs from nonpregnant myometrium (Fig. 2a), while a deviation above $30^{\circ}$ was attained in one preparation or even $72^{\circ}$ in TCs from pregnant myometrium (Fig. 2b).

Twenty-five percent of TCs from pregnant uterus present local thickening of the telopode upon LLLS (Fig. 2c(a-c)). The local thickening phenomenon was directly correlated with a delayed telopodal response to stimulation $(>1,000 \mathrm{~s})$. The great variability of response to LLLS in pregnant myometrium must be considered as very important, probably being correlated with distinct uterine morphological characteristics in each patient.

We found that mibefradil modulates LLLS effect on TLE from pregnant myometrium. It is already known that mibefradil inhibits the bioelectrical signal and uterine 
Fig. 1 TCs in myometrial cell culture (fourth passage, day 3). a Phase contrast microscopy of typical a TC with very long telopodes. b Distribution of CD 34 immunopositivity in the same TC. c Cells that display the TC morphology express PDGFR $\alpha$. Scale bar $=50 \mu \mathrm{m}$
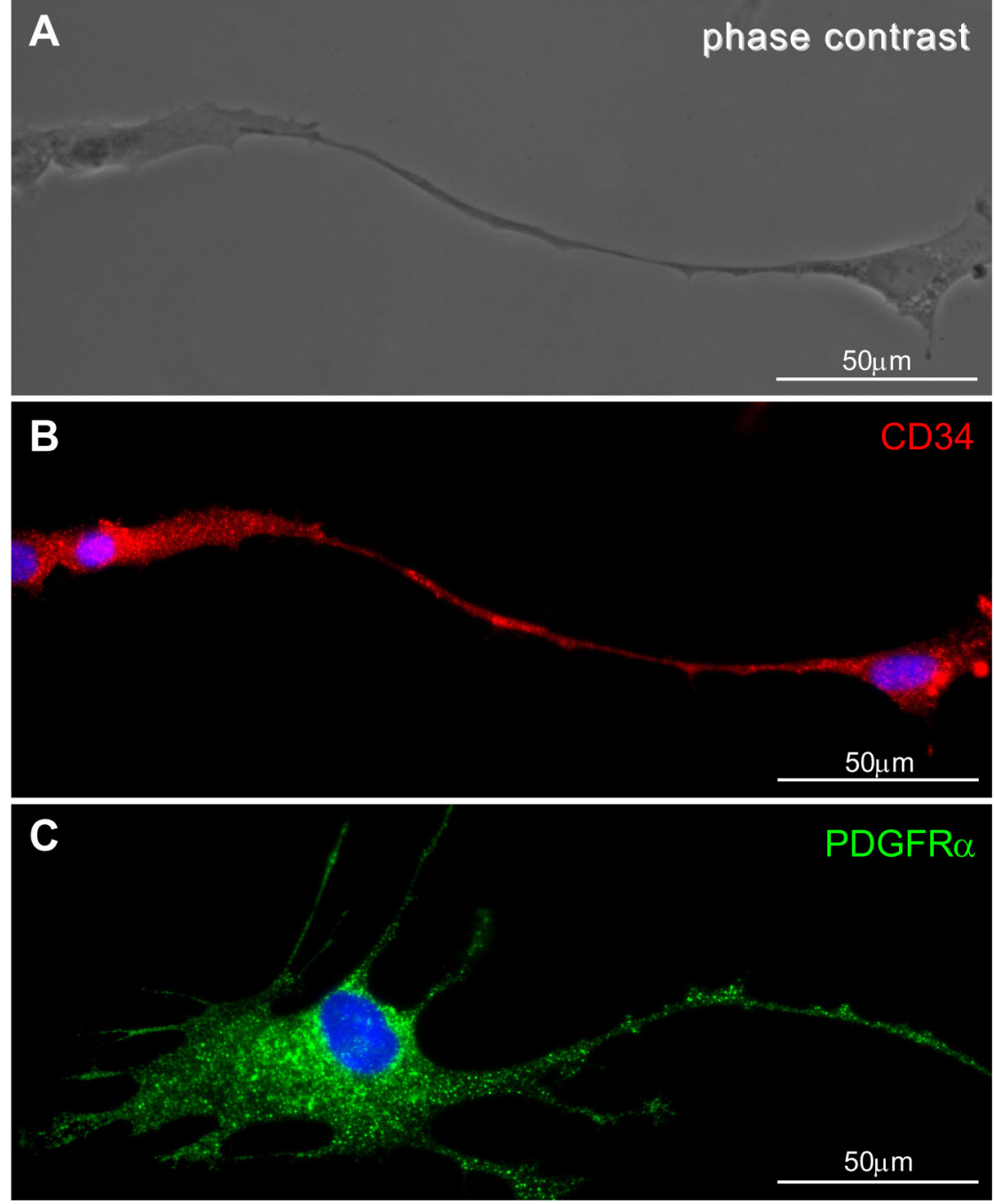

contractile forces [25], and we have tested the combined effect of mibefradil and LLLS on TCs. TCs from pregnant myometrium have been exposed to mibefradil $(1 \mu \mathrm{M})$, a selective antagonist of T-type calcium channels [26].

Acute (30 min) and chronic ( $24 \mathrm{~h})$ exposure to mibefradil was done, and the LLLS effect on TLE growth rate was measured. In pregnant myometrium, the LLLS effect was tested on TCs per se (control; Fig. $4 \mathrm{a}(\mathrm{a}-\mathrm{c})$ ) and on TCs exposed to mibefradil $(1 \mu \mathrm{M}$; Fig. $4 \mathrm{~b}(\mathrm{a}-\mathrm{c}))$.

The chronic exposure to mibefradil determined a decrease in the growth rate, $5.7 \pm 0.8 \mu \mathrm{m} / \mathrm{min}(n=3)$, that is significantly lower than that in control conditions $(9.7 \pm 0.4 \mu \mathrm{m} / \mathrm{min}, n=3$; $p<0.05$, paired Student's $t$ test; Fig. 5). The control value of the growth rate for pregnant myometrium was found to be different from the above-reported values. It should be noted that the LLLS growth rate after acute mibefradil treatment in pregnant myometrium is below the growth rate for control nonpregnant myometrium ( $p<0.05$, unpaired Student's $t$ test). After chronic exposure to mibefradil, LLLS performed on
TCs from pregnant myometrium indicated an inhibition of the growth process.

The LLLS-induced deviation in telopodal growth direction was also monitored. Acute mibefradil treatment accentuates the angle of deviation above $30^{\circ}$ (Fig. $4 \mathrm{~b}$ ). However, due to the large variability of responses of the TCs from pregnant myometrium to LLLS, it is difficult to estimate the exact increase in the angle of deviation due to acute mibefradil exposure.

The same experiment was performed on TCs from nonpregnant myometrium, and both acute and chronic mibefradil exposures completely abolished the TLE growth rate upon LLLS.

\section{Discussion}

This study provides evidence for the presence of TCs in myometrial interstitial cell cultures, identified by their 
Fig. 2 Comparative LLLS effect on TCs from nonpregnant and pregnant myometrium cell cultures (fourth passage, day 3 ). a TLE growth of TCs from nonpregnant myometrium. The angle of the TLE deviation is $\leq 30^{\circ}$. The time course of this effect is $20 \mathrm{~s}$. b TLE growth of TCs from pregnant myometrium. The angle of the TLE deviation is between $30^{\circ}$ and $72^{\circ}$, while the time course of this effect is longer- $1 \mathrm{~min}$ and $6 \mathrm{~s}$. Scale bar $=10 \mu \mathrm{m}$. c Telopodal local thickening upon optical tweezer stimulation was obtained in $25 \%$ of TCs from pregnant myometrial cell culture. Scale bar $=40 \mu \mathrm{m}$. Yellow arrows indicate the TLE subjected to LLLS. The black arrows indicate the direction of the TLE. Each red square evidences the region of interest for the LLLS effect
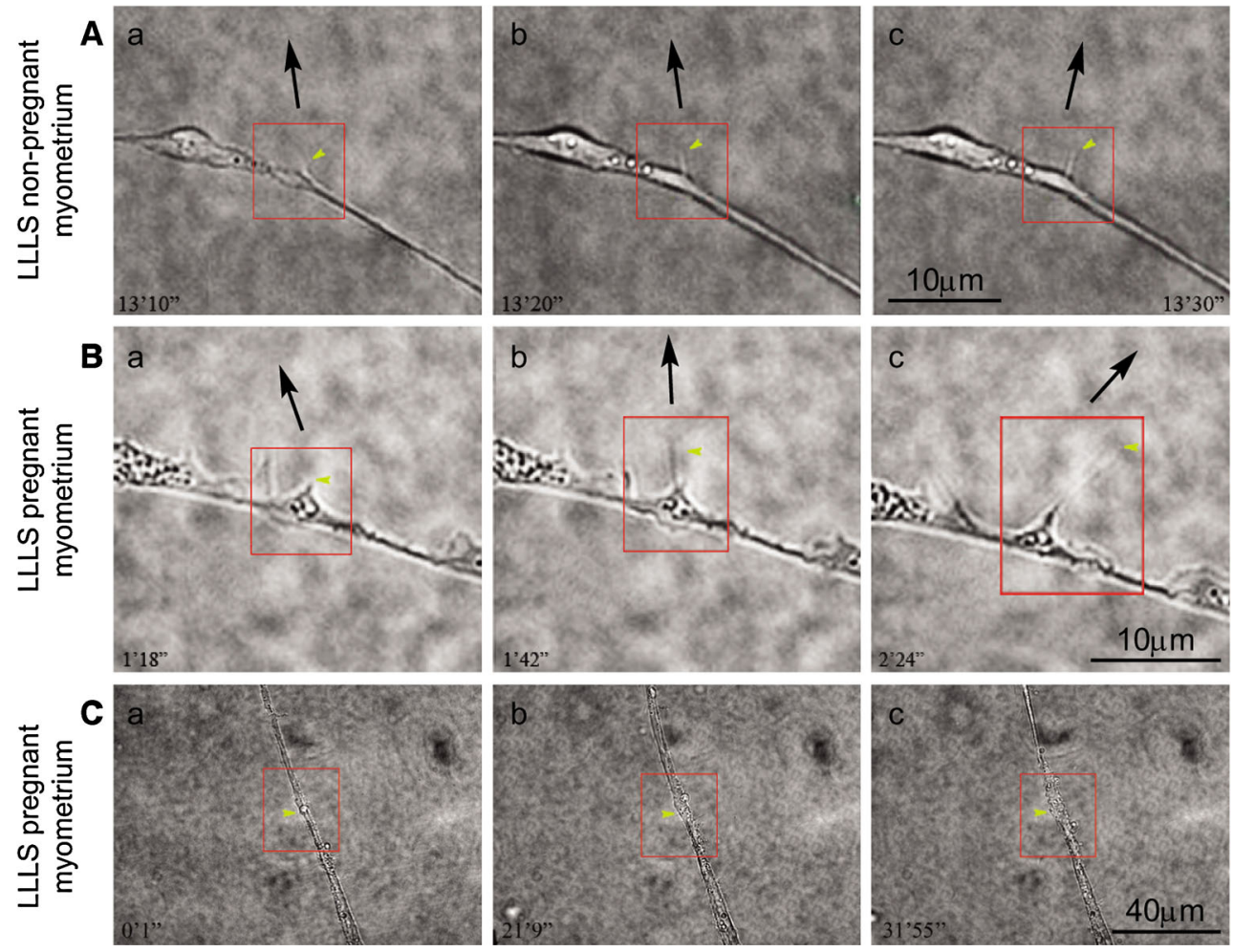

morphology and CD34 and PDGFR $\alpha$ positivity. Our findings are in correlation with recent data suggesting that $\operatorname{PDGFR} \alpha$ positive and CD34-positive cells are the same cell type - the TCs [6-8].

Low-level laser therapy (LLLT) has an extensive medical use, and the idea of using sub-thermal doses of laser light dated from the early 1970s (see reviews [27, 28]). Although

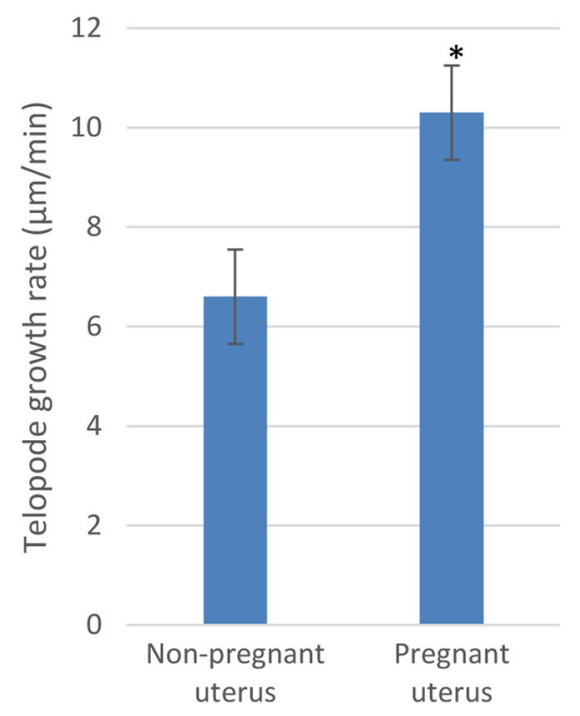

Fig. 3 The comparative average of telopodal growth rate upon LLLS between TCs from nonpregnant and pregnant myometrium. ${ }^{*} p<0.01$, unpaired Student's $t$ test the medical use of high power NIR lasers in endometrial laser intrauterine thermotherapy $[29,30]$ or endometrial resection and ablation [31,32] is a clinical routine, uterine LLLT interventions are still pioneering. Therefore, our data on cellular mechanisms underlying in vitro LLLS of TCs are pushing forward this domain.

The differences in TC reactivity to LLLS highlighted by our study in human nonpregnant and pregnant myometrium are not surprising since previous morphological studies have proved significant differences in telopodal width and in podomic thickness and gauge in human nonpregnant and pregnant myometrium [12]. A possible explanation of TC differences in reactivity to LLLS might be related to distinct cytoskeleton characteristics of TCs in pregnant uterus. A recent study indicates that the expression of integrins (ITGA5, ITGA7, ITGAV, and ITGB3) increases in pregnant myometrium, and there is important colocalization with focal adhesion proteins in human myometrium at term, and it was also emphasized that mechanical signals are transmitted from the extracellular matrix through focal adhesions in pregnant human myometrium [33].

Frequency domain NIR spectroscopy has proved that optical properties of the human uterine cervix are influenced by the hormonal status depending on the phases of menstrual cycle [34] or by pregnancy [35]. Therefore, we might suppose that the uterine remodeling in pregnancy is correlated with changes in cellular dynamics and morphology, and TCs are actively participating in this $3 \mathrm{D}$ network reorganization. All 

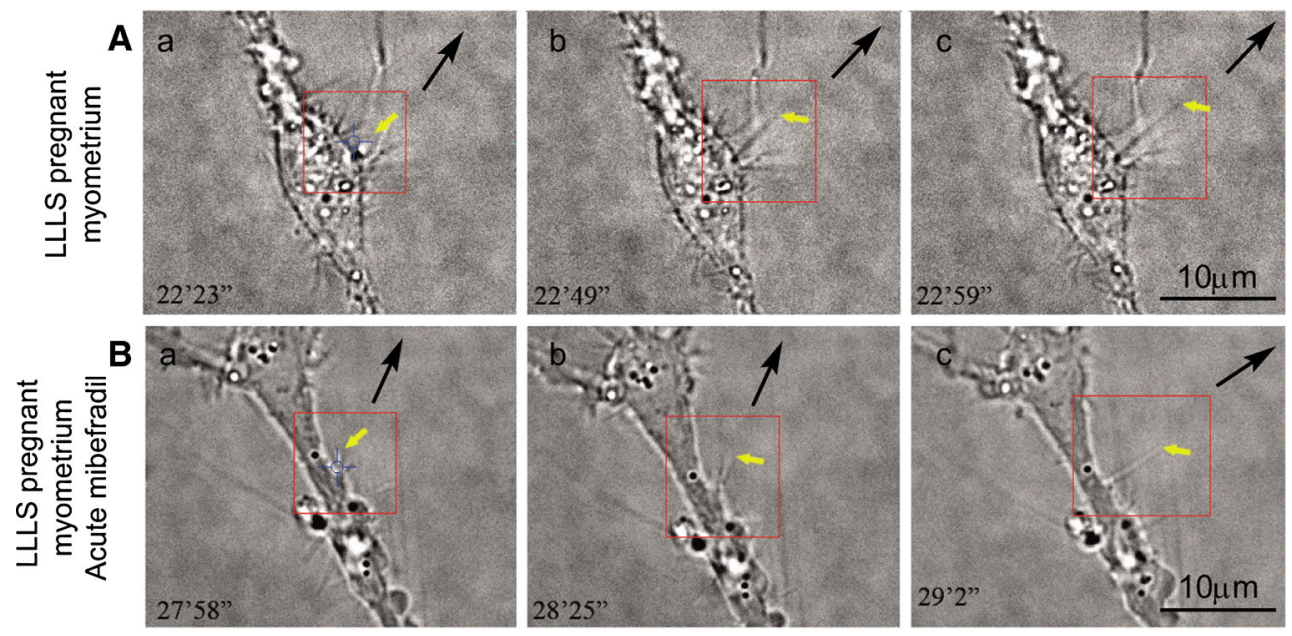

Fig. 4 Mibefradil effect on TLE upon LLLS in pregnant myometrium (myometrial interstitial cell culture at fourth passage, day 3). a Untreated TCs exposed to LLLS were considered as control. The time course of LLLS effect in these images $(a-c)$ is $36 \mathrm{~s}$. We can observe how a TLE grows (yellow arrow). b Mibefradil $(1 \mu \mathrm{M})$ was perfused for $30 \mathrm{~min}$, and afterwards, TCs were re-exposed to LLLS. Comparison of the TLE

these optical properties can be distinctly exploited in LLLS on human pregnant and nonpregnant myometrium.

It was suggested that the TC network may be involved in mechanical modulations and remodeling in various organs [36]. In particular, this issue is very interesting in the uterus, as the mechanical modulation exerted by TCs on other cell types can be distinct in pregnant and nonpregnant myometrium. The differences founded in TC reactivity to LLLS can be related to extensive changes in cell-cell communication residing in exosomes trafficking through the telopodes. A very recent challenging idea considers the cross talk between TCs-exosomes-gap junctions-cytoskeleton to be the equivalent of the primitive nervous system [11].

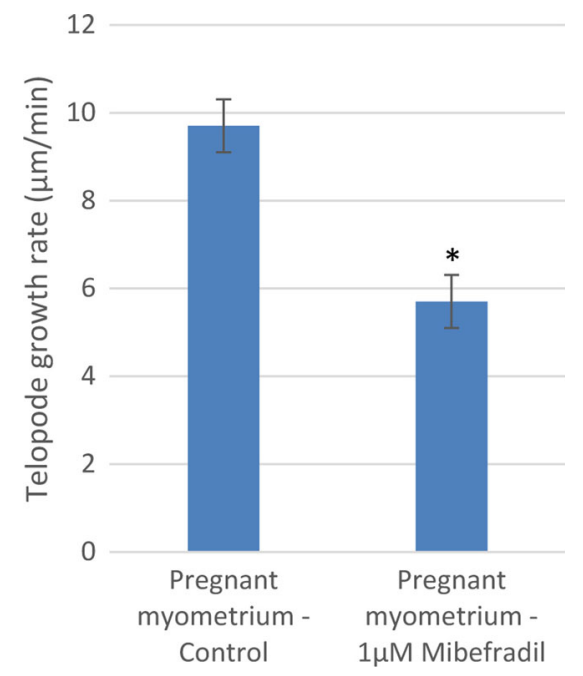

Fig. 5 The comparative average growth rate of TLE upon LLLS between TCs from pregnant myometrium before and after acute mibefradil (30 min) treatment. * $p<0.05$, paired Student's $t$ test growth rate reveals that in $1 \mathrm{~min}$ and $4 \mathrm{~s}$, the length of TLE is approximately the same as that in control and that the angle of the deviation is slightly above $30^{\circ}$. Yellow arrows indicate the TLE subjected to LLLS. The black arrows indicate the direction of the TLE. Each red square evidences the region of interest for the LLLS effect. Scale bar $=10 \mu \mathrm{m}$

Cytoskeleton elements have had also being implicated as a substrate responsible for guidance of neuronal growth upon optical stimulation [19]. Telopodes also contain cytoskeleton elements, proved very recently, when the cellular TC proteome was analyzed and revealed the presence of proteins from intermediate filaments (56\%), actin cytoskeleton (19\%), and microtubule $(6 \%)$ [37]. The higher growth plasticity of the telopodes with respect to the neuronal growth cone should be taken into account since this parallelism can be further exploited, as the growth rate reported in our study is significantly higher than the previous data on neuronal optical guidance $[21,22]$.

The contribution of TCs in mechanical stretching during uterine contraction is still to be understood; nevertheless, membrane stiffness properties tested by LLLS can reveal interesting molecular mechanisms. It is of particular interest the fact that the telopodes of TCs from nonpregnant myometrium are intensively positive for vimentin [38], a cytoskeleton protein. A recent study proved that vimentin is very important in cytoplasmic stiffness of optically trapped mouse embryonic fibroblasts using a 1,064-nm Nd:YAG laser at a power of $200 \mathrm{~mW}$ [39]. The differences that we observed between pregnant and nonpregnant myometrium can possibly be explained in terms of telopodal stiffness due to vimentinbased anchoring mechanisms. Additionally, TCs from the human myometrium are positive for PDGFR, and PDGFR signaling might also modulate the telopodal membrane mechanical properties, in an analog manner, as described in vascular smooth muscle cells [40].

In conclusion, taking into consideration the profound physiological myometrial remodeling during pregnancy, which involves extensive structural and molecular changes, our 
findings suggest that the molecular mechanisms activated in TCs by means of LLLS are distinct in human nonpregnant and pregnant myometrium. Therefore, LLLT in human uterus should consider these cellular differences in pregnant and nonpregnant myometrium, and the laser power and exposure time should be adequately chosen.

Acknowledgments This work was supported by a grant from the Romanian National Authority for Scientific Research, CNCS UEFISCDI, project number 82/2012 PN-II-PT-PCCA-2011-3.1-0553. Dr. B.M. Radu is financed by the Italian ministerial fellowship D.M. 198/2003. We are grateful to Dr. Laura C. Ceafalan and T. Regalia for their discussion and expert technical assistance. We also thank Dr. Mihai Radu for his useful comments and suggestions that helped to improve this manuscript.

Open Access This article is distributed under the terms of the Creative Commons Attribution License which permits any use, distribution, and reproduction in any medium, provided the original author(s) and the source are credited.

\section{References}

1. Popescu LM, Ciontea SM, Cretoiu D (2007) Interstitial Cajal-like cells in human uterus and fallopian tube. Ann N Y Acad Sci 1101: 139-165. doi:10.1196/annals.1389.022

2. Hutchings G, Williams O, Cretoiu D, Ciontea SM (2009) Myometrial interstitial cells and the coordination of myometrial contractility. J Cell Mol Med 13:4268-4282. doi:10.1111/j.1582-4934.2009.00894. $x$

3. Popescu LM, Faussone-Pellegrini MS (2010) TELOCYTES - a case of serendipity: the winding way from interstitial cells of Cajal (ICC), via interstitial Cajal-like cells (ICLC) to TELOCYTES. J Cell Mol Med 14:729-740. doi:10.1111/j.1582-4934.2010.01059.x

4. Cretoiu SM, Cretoiu D, Popescu LM (2012) Human myometriumthe ultrastructural 3D network of telocytes. J Cell Mol Med 16:2844 2849. doi:10.1111/j.1582-4934.2012.01651.x

5. Mou Y, Wang Y, Li J, Lü S, Duan C, Du Z, Yang G, Chen W, Zhao S, Zhou J, Wang C (2013) Immunohistochemical characterization and functional identification of mammary gland telocytes in the selfassembly of reconstituted breast cancer tissue in vitro. J Cell Mol Med 17:65-75. doi:10.1111/j.1582-4934.2012.01646.x

6. Vannucchi MG, Traini C, Manetti M, Ibba-Manneschi L, FaussonePellegrini MS (2013) Telocytes express PDGFR $\alpha$ in the human gastrointestinal tract. J Cell Mol Med 17:1099-1108. doi:10.1111/ jcmm. 12134

7. Milia AF, Ruffo M, Manetti M, Rosa I, Conte D, Fazi M, Messerini L, Ibba-Manneschi L (2013) Telocytes in Crohn's disease. J Cell Mol Med. 17:1525-1536. doi:10.1111/jcmm. 12177

8. Xiao J, Wang F, Liu Z, Yang C (2013) Telocytes in liver: electron microscopic and immunofluorescent evidence. J Cell Mol Med. 17: 1537-1542. doi:10.1111/jcmm.12195

9. Nicolescu MI, Bucur A, Dinca O, Rusu MC, Popescu LM (2012) Telocytes in parotid glands. Anat Rec (Hoboken) 295:378-385. doi: 10.1002/ar.21540

10. Nicolescu MI, Popescu LM (2012) Telocytes in the interstitium of human exocrine pancreas: ultrastructural evidence. Pancreas 41:949 956. doi:10.1097/MPA.0b013e31823fbded

11. Smythies J, Edelstein L (2013) Telocytes, exosomes, gap junctions and the cytoskeleton: the makings of a primitive nervous system? Front Cell Neurosci. doi:10.3389/fncel.2013.00278
12. Cretoiu SM, Cretoiu D, Marin A, Radu BM, Popescu LM (2013) Telocytes: ultrastructural, immunohistochemical and electrophysiological characteristics in human myometrium. Reproduction 145: 357-370. doi:10.1530/REP-12-0369

13. Suciu L, Nicolescu MI, Popescu LM (2010) Cardiac telocytes: serial dynamic images in cell culture. J Cell Mol Med 14:2687-2692. doi: 10.1111/j.1582-4934.2010.01185.x

14. Popescu LM, Gherghiceanu M, Cretoiu D, Radu E (2005) The connective connection: interstitial cells of Cajal (ICC) and ICC-like cells establish synapses with immunoreactive cells. Electron microscope study in situ. J Cell Mol Med 9:714-730. doi:10.1111/j.15824934.2005.tb00502.x

15. Cretoiu D, Cretoiu SM, Simionescu AA, Popescu LM (2012) Telocytes, a distinct type of cell among the stromal cells present in the lamina propria of jejunum. Histol Histopathol 27:1067-1078

16. Popescu LM, Nicolescu MI (2013) Telocytes and stem cells. In: dos Santos Goldenberg RC, Campos de Carvalho AC (eds) Resident stem cells and regenerative therapy. Academic Press, Oxford, pp 205-231

17. Ehrlicher A, Betz T, Stuhrmann B, Koch D, Milner V, Raizen MG, Kas J (2002) Guiding neuronal growth with light. Proc Natl Acad Sci U S A 99:16024-16028. doi:10.1073/pnas.252631899

18. Graves CE, McAllister RG, Rosoff WJ, Urbach JS (2009) Optical neuronal guidance in three-dimensional matrices. J Neurosci Methods 179:278-283. doi:10.1016/j.jneumeth.2009.02.004

19. Franze K, Guck J (2010) The biophysics of neuronal growth. Rep Prog Phys 73:094601. doi:10.1088/0034-4885/73/9/094601

20. Stevenson DJ, Gunn-Moore F, Dholakia K (2010) Light forces the pace: optical manipulation for biophotonics. J Biomed Opt 15: 041503. doi:10.1117/1.3475958

21. Ebbesen CL, Bruus H (2012) Analysis of laser-induced heating in optical neuronal guidance. J Neurosci Methods 209:168-177. doi:10. 1016/j.jneumeth.2012.02.006

22. Campeanu RA, Flonta ML (2013) Optical stimulation of neuronal growth. Rom J Biophys 23:159-170

23. Albrecht-Buehler G (1991) Surface extensions of 3 T3 cells towards distant infrared light sources. J Cell Biol 114:493-502. doi:10.1083/ jcb.114.3.493

24. Stevenson DJ, Lake TK, Agate B, Gárcés-Chávez V, Dholakia K, Gunn-Moore F (2006) Optically guided neuronal growth at near infrared wavelengths. Opt Express 14:9786-9793. doi:10.1117/12. 680554

25. Young RC, Zhang P (2005) Inhibition of in vitro contractions of human myometrium by mibefradil, a T-type calcium channel blocker: support for a model using excitation-contraction coupling, and autocrine and paracrine signaling mechanisms. J Soc Gynecol Investig 12:e7-e12

26. Leuranguer V, Mangoni ME, Nargeot J, Richard S (2001) Inhibition of T-type and L-type calcium channels by mibefradil: physiologic and pharmacologic bases of cardiovascular effects. J Cardiovasc Pharmacol 37:649-661. doi:10.1097/00005344-200106000-00002

27. King PR (1989) Low level laser therapy: a review. Lasers Med Sci 4: 141-150. doi:10.1007/BF02032427

28. Lucas C, Stanborough RW, Freeman CL, De Haan RJ (2000) Efficacy of low-level laser therapy on wound healing in human subjects: a systematic review. Lasers Med Sci 15:84-93. doi:10. 1007/s101030050053

29. Jones K, Abbott J, Hawe J, Sutton C, Garry R (2001) Endometrial laser intrauterine thermotherapy for the treatment of dysfunctional uterine bleeding: the first British experience. BJOG 108:749-753. doi:10.1016/S0306-5456(00)00176-5

30. Perino A, Castelli A, Cucinella G, Biondo A, Pane A, Venezia R (2004) A randomized comparison of endometrial laser intrauterine thermotherapy and hysteroscopic endometrial resection. Fertil Steril 82:731-734. doi:10.1016/j.fertnstert.2004.01.045 
31. Fergusson RJ, Lethaby A, Shepperd S, Farquhar C (2013) Endometrial resection and ablation versus hysterectomy for heavy menstrual bleeding. Cochrane Database Syst Rev 11, CD000329. doi:10.1002/14651858.CD000329.pub2

32. Kroft J, Liu G (2013) First- versus second-generation endometrial ablation devices for treatment of menorrhagia: a systematic review, meta-analysis and appraisal of economic evaluations. J Obstet Gynaecol Can 35:1010-1019

33. Burkin HR, Rice M, Sarathy A, Thompson S, Singer CA, Buxton IL (2013) Integrin upregulation and localization to focal adhesion sites in pregnant human myometrium. Reprod Sci 20:804-812. doi:10. 1177/1933719112466303

34. Matzinger B, Wolf M, Baños A, Fink D, Hornung R (2009) Optical properties, physiologic parameters and tissue composition of the human uterine cervix as a function of hormonal status. Lasers Med Sci 24:561-566. doi:10.1007/s10103-008-0611-x

35. Hornung R, Spichtig S, Baños A, Stahel M, Zimmermann R, Wolf M (2010) Frequency-domain near-infrared spectroscopy of the uterine cervix during regular pregnancies. Lasers Med Sci 26:205-212. doi: 10.1007/s10103-010-0832-7
36. Cretoiu SM, Cretoiu D, Simionescu AA, Popescu LM (2012) Telocytes in human fallopian tube and uterus express estrogen and progesterone receptors. In: Kahn SM (ed) Sex steroids. Intech, Rijeka, pp 91-114

37. Zheng Y, Cretoiu D, Yan GQ, Cretoiu SM, Popescu LM, Wang X (2014) Comparative proteomic analysis of human lung telocytes with fibroblasts. J Cell Mol Med. 18:568-589. doi:10.1111/jcmm.12290

38. Ciontea SM, Radu E, Regalia T, Ceafalan L, Cretoiu D, Gherghiceanu M, Braga RI, Malincenco M, Zagrean L, Hinescu ME, Popescu LM (2005) C-kit immunopositive interstitial cells (Cajal-type) in human myometrium. J Cell Mol Med 9:407-420. doi:10.1111/j.1582-4934.2005.tb00366.x

39. Guo M, Ehrlicher AJ, Mahammad S, Fabich H, Jensen MH, Moore JR, Fredberg JJ, Goldman RD, Weitz DA (2013) The role of vimentin intermediate filaments in cortical and cytoplasmic mechanics. Biophys J 105:1562-1568. doi:10.1016/j.bpj.2013.08.037

40. Brown XQ, Bartolak-Suki E, Williams C, Walker ML, Weaver VM, Wong JY (2010) Effect of substrate stiffness and PDGF on the behavior of vascular smooth muscle cells: implications for atherosclerosis. J Cell Physiol 225:115-122. doi:10.1002/jcp.22202 